УДК 619:612.015.31:615.272.2

ЙОДНАЯ НЕДОСТАТОЧНОСТЬ: ПРОБЛЕМЫ И ОБОСНОВАНИЕ НОВОГО ПОДХОДА ЕЕ ПРОФИЛАКТИКИ

ЕВГЛЕВСКАЯ Е.П., кандидат сельскохозяйственных наук, доцент.

ЕВГЛЕВСКИЙ Ал.А., доктор ветеринарных наук, профессор, главный научный сотрудник Курского Федерального аграрного научного центра, заведующий лабораторией «Ветеринарная медицина» evgl46@yandex.ru; 8-919-210-71-60.

ЕВГЛЕВСКАЯ (СУЛЕЙМАНОВА) Т.А., кандидат экономических наук, доцент Курского института кооперации.

Реферат. В статье представлен материал, посвященный одной из глобальных, жизненно важных проблем человечества - дефициту йода. Принимая во внимание факт, что в условиях постоянного дефицита йода весьма проблемно обеспечить здоровье высокопродуктивных животных, вопросы профилактики йоддефицитных состояний являются экономически значимыми для промышленного животноводства. На страницах данной статьи впервые в ветеринарии обозначены перспективы применения в незаразной и инфекционной патологии нового йодметаболического препарата на основе хорошо известного в ветеринарии и медицине препарата йодинол и янтарной кислоты. Сравнительное тестирование комплексного препарата и фармакопейного йодинола на телятах с клинически выраженным йоддефицитным состоянием свидетельствуют о том, что модифицированный йодинол при внутримышечном введении обеспечивает высокую эффективность коррекции патобиохимических процессов и нормализацию гормональной функции щитовидной железы. Новые качества модифицированного йодинола открывают новые перспективы его применения в инфекционной и незаразной патологии.

Ключевые слова: йодная недостаточность, йодинол, янтарная кислота, модифицированный йодинол, клинические наблюдения, биохимический статус, тиреоидные гормоны, коррекция метаболизма.

\title{
IODINE DEFICIENCY: PROBLEMS AND JUSTIFICATION OF A NEW APPROACH TO ITS PREVENTION AND CORRECTION
}

EVGLEVSKAYA E.P., candidate of agricultural Sciences, associate Professor.

EVGLEVSKY Al.A., doctor of veterinary Sciences, Professor, chief researcher of the Kursk Federal agricultural research center, head of the laboratory "Veterinary medicine"; tel. 8-919-210-71-60.

EVGLEVSKAYA (SULEYMANOVA) T.A., candidate of economic Sciences, associate Professor of Kursk Institute of cooperation.

Essay. The article presents the material devoted to one of the global, vital problems of mankind iodine deficiency Taking into account the fact that in the conditions of constant iodine deficiency is very problematic to ensure the health of highly productive animals, the issues of prevention of iodine deficiency are economically important for industrial livestock. On the pages of this article for the first time in veterinary medicine the prospects of application in non-infectious and infectious pathology of a new iodometabolic preparation on the basis of well-known in veterinary medicine and medicine preparation Iodinol and succinic acid. Comparative testing of the complex preparation and Pharmacopoeia Iodinol on calves with clinically expressed iodine deficiency state indicates that the modified Iodinol with in- 


\section{ДИАГНОСТИКА БОЛЕЗНЕЙ И ТЕРАПИЯ ЖИВОТНЫХ, ПАТОЛОГИЯ, ОНКОЛОГИЯ И МОРФОЛОГИЯ ЖИВОТНЫХ}

tramuscular administration provides high efficiency of correction of pathobiochemical processes and normalization of hormonal function of the thyroid gland. New qualities of the modified Iodinol open new prospects of its application in infectious and non-infectious pathology.

Keywords: iodine deficiency, Iodinol, succinic acid, modified Iodinol, clinical observations, biochemical status, thyroid hormones, metabolic correction.

Введение. Одной из глобальных, жизненно важных проблем человечества является дефицит йода. «SOS для человечества» - так эксперты Всемирной организации здравоохранения называют проблему йодного дефицита. И вот почему. В настоящее время йододефицитные заболевания являются самой распространенной неинфекционной патологией, как в нашей стране, так и в мире. По причине йодной недостаточности ежегодно в России рождается порядка 130 тысяч детей с необратимыми изменениями в развитии ЦНС, снижением в интеллектуальном и умственном развитии, более 50 млн. страдают различными заболеваниями $[1,2]$. Эти данные наиболее показательно иллюстрируют проблему йодной недостаточности и ее последствия. И это неудивительно. Почти все население России проживает в районах с легким, умеренным или тяжелым дефицитом йода, и только на морском побережье йода вполне достаточно $[1,2]$. В настоящее время в большинстве стран, испытывающих острый дефицит йода, разработаны государственные программы по профилактике йоддефицитных состояний не только у людей, но и у животных. К примеру, в странах ЕС принят максимально безопасный уровень содержания йода в кормах кур для получения от них йодированных яиц (5000 мкг/кг). Такой уровень йода позволяет улучшить не только продуктивное здоровье кур, но получать от них яйца с содержанием йода до 70 мкг/яйцо. В основу стратеги ликвидации йодной недостаточности положено обязательное использование йодированной соли при производстве продуктов питания и кормов для животных. Казалось простой и доступный метод профилактики йодной недостаточности, тем не менее, в нашей стране он не получил должного понимания и имеет ограниченное применение даже для людей $[1,2]$. Во многом это объясняется отсутствием государственной Программы по профилактике йоддефицитных состояний среди населения. В этой связи йодированная соль ограниченно используется лишь на бытовом уровне. На государственном уровне в нашей стране пока нет обязательных нормативных положений по исполь- зованию йодированной соли при производстве продуктов питания. Проблема йодной недостаточности, несмотря на научные исследования, в практической ветеринарии никак не обозначалась [3]. Ветеринарные специалисты, как правило, связывают нарушения роста и развития молодняка, высокую чувствительность организма к возбудителям эндогенных инфекций, нарушения обмена веществ, иммунодефицитные состояния, снижение продуктивности и воспроизводительной способности животных с различными неблагоприятными факторами, но никак не с дефицитом йода. При этом упускается из внимания тот факт, что йод является ключевым элементом в обеспечении здоровья животного организма. Дело в том, что все виды обмена веществ: - белковый, жировой, углеводный, макро- и микроэлементный, энергетический зависят от гормонов щитовидной железы. Однако в условиях постоянного дефицита йода невозможна нормальная выработка гормонов щитовидной железы, что влечет глубокие нарушения всех видов обмена веществ [1-4]. В этой связи сбой в работе щитовидной железы сопровождается развитием тяжелых патобиохимических процессов, что, в конце концов, ведет к клиническому проявлению патофизиологических состояний. Так, у коров йодная недостаточность чаще всего проявляется суставной патологией с развитием артритов и артрозов, патологией беременности и нарушением воспроизводительной функции, у телят и молодняка низкой жизнеспособностью и высокой чувствительностью к возбудителям эндогенных инфекций. При йодной недостаточности невозможно защитить организм от возбудителей инфекций. Не помогут ни вакцины, ни самые сильные антибиотики. На фоне йодной недостаточности применение тех или иных лекарственных средств, витаминных препаратов, средств стимуляции обмена веществ или системы иммунитета, не будет иметь выраженного позитивного результата. Принимая во внимание факт, что в условиях постоянного дефицита йода весьма проблемно обеспечить здоровье высокопродуктивных животных, вопросы профилактики йоддефицитных состояний яв- 


\section{ДИАГНОСТИКА БОЛЕЗНЕЙ И ТЕРАПИЯ ЖИВОТНЫХ, ПАТОЛОГИЯ, ОНКОЛОГИЯ И МОРФОЛОГИЯ ЖИВОТНЫХ}

ляются экономически значимыми для промышленного животноводства. Несмотря на то, что наиболее простым и доступным способом устранения йодной недостаточности в организме человека и животных является включение в рацион питания йодированной соли, тем не менее, такой метод по ряду обстоятельств не может быть оптимальным для специалистов практической ветеринарии. Прежде всего, кормовой метод применения биологически активных добавок исключает возможность дозировано проводить лечебную или превентивную обработку. Что касается йодированной соли, то приходится принимать во внимание факт, что концентрация йода в ней нестабильна и при хранении значительно снижается, вплоть до полной потери. В этой связи, применение йодированной соли отдельно при добавлении в корм или в составе премиксов не может считаться эффективным подходом. Более рациональным подходом профилактики заболеваний, связанных с йодной недостаточностью, в том числе обеспечения оптимальной регуляции обменных процессов в организме, может иметь применение хелатных соединений. Именно это обстоятельство было принято во внимание при определении авторских поисковых исследований при разработке комплексного йодметаболического препарата, пригодного для инъекционного метода введения.

Цель и задачи исследований - теоретическое обоснование применения янтарной кислоты для потенцирования биологической активности йодинола и оценка эффективности инъекционного применения комплексного препарата для коррекции метаболизма при клинически выраженной йодной недостаточности у коров.

Материал и методика исследования. Объектом для клинических опытов являлись телята с наличием признаков микседемы, нарушением роста волосяного покрова и его своеобразной курчавостью и взъерошенностью, алопециями. По результатам биохимических исследований, в т.ч. с определением тиреоидных гормонов триийодтиронина СТ3 и тироксина СТ4, были отобраны животные - «доноры» имевшие наиболее близкие показатели. Таких в каждой группе было по 5 особей. На телятах первой опытной группы тестировали модифицированный йодинол, а на животных второй группы фармакопейный. Тестируемые препараты вводили внутримышечно в объеме 5 мл (20 мг йода) с кратностью раз в 5 дней. Контроль за состоянием здоровья подопытных животных проводили путем клинических наблюдений и сопоставления биохимических показателей. Биохимические исследования провели на автоматическом анализаторе Eos Bravo forte (Hospitex Diagnostics, Italia) с использованием дагностических наборов «Абрис» Россия.

Результаты исследования. На страницах данной статьи мы, впервые в ветеринарии обращаем внимание на открывающиеся перспективы применения в незаразной и инфекционной патологии нового йодметаболического препарата на основе хорошо известного в ветеринарии и медицине препарата йодинол и янтарной кислоты.

Препарат - йодинол представляет собой соединение йода-йодида с высокополимерами, в частности с поливиниловым спиртом или крахмалом. В 1960 году препарат йодинол был официально зарегистрирован Фармкомитетом СССР. В 1962 г. было дано разрешение на его применение в медицинской практике. С тех пор накоплен огромный клинический опыт применения йодинола в медицине и ветеринарии. Многих до сего времени удивляет поистине уникальная лечебная эффективность применения йодинола при инфекционной и незаразной патологии. Йодинол, в отличие от элементарного йода, малотоксичен, обладает противовирусной, антимикробной и антигрибковой активностью.

Уникальный спектр метаболического действия янтарной кислоты предопределил возможность её использования в качестве метаболического компонента. И это не случайно. Янтарная кислота является мощным стимулятором обмена веществ живой клетки. Объектом действия янтарной кислоты являются клетки и ткани, находящиеся в состоянии возбуждения или патологически измененные. Стимулирующее действие янтарной кислоты особо выражено при ослаблении организма и его заболевании. Абсолютная безвредность янтарной кислоты и ее солей (сукцинатов), ее способность оказывать положительный эффект даже при весьма низких дозировках (10 мг/кг) делают ее весьма ценным компонентом при разработке нового поколения, так называемых «умных» лекарств, пищевых и кормовых добавок [5-7].

В настоящее время она является универсальным компонентом, широко используемым для улучшения фармакологической активности лекарственных средств [5]. 


\section{ДИАГНОСТИКА БОЛЕЗНЕЙ И ТЕРАПИЯ ЖИВОТНЫХ, ПАТОЛОГИЯ, ОНКОЛОГИЯ И МОРФОЛОГИЯ ЖИВОТНЫХ}

Работая в данном направлении много лет, у нас накоплен большой опыт по ее применению для качественного улучшения целого ряда хорошо известных в ветеринарии препаратов, имеющих побочные эффекты или противопоказания $[6,7]$. Препарат йодинол, также имеет ограничения и противопоказания для применения в клинической практике.

В наших исследованиях установлено, что включение в состав йодинола янтарной кислоты в количестве $1 \%$ или сукцината натрия с аналогичной концентрацией янтарной кислоты, позволило качественно улучшить его фармакологические свойства, в частности, усилить его метаболическую активность, что воплотилось в реализацию авторских научных разработок [8-11].

Отрадно отметить, что параллельно с нами, аналогичная разработка осуществлена на Луганском ХимФармЗаводе. Еще один аспект, который мы обозначаем на страницах данной статьи, относится к возможности инъекционного метода применения йодметаболического препарата. Вплоть до последнего времени инъекционный метод применения препарата йодинол в клинической ветеринарии не рассматривался и не практиковался. Основным сдерживающим фактором являлись нормативные положения, которые допускали лишь наружное и оральное применение препарата. Следует отметить, что еще автор препарата йодинол В.О. Мохнач первый допускал возможность применения йодинола не только орально или наружно, но и подкожно, внутримышечно, внутривенно. Этим он заложил основу для расширения сферы клинического применения препарата йодинол.

Возможность проведения клинических опытов представилась при массовом проявлении признаков йодной недостаточности у телят мо- лочного комплекса «Благодатенский». Исходный клинический статус телят - отставание в росте и развитии, нарушение роста волосяного покрова, его своеобразная курчавость и взъерошенность, алопеции на голове и по телу, дерматиты, с преимущественной локализацией в области дистального отдела конечностей. У большинства телят имелись признаки микседемы. Такой фон являлся по сути «идеальным» для оценки клинической эффективности модифицированного йодинола. В ходе клинических наблюдений установлено, что выраженные изменения у подопытных телят первой группы обозначились уже спустя сутки. Вначале это проявилось хорошо выраженным улучшением аппетита. На 14-15 сутки у телят первой опытной группы выраженно улучшилось состояние волосяного покрова. В этот же период отмечен рост волос на бесшерстных участках (редуцирование алопеций). Результаты биохимических исследований сыворотки крови на 10 и 20 сутки были сопоставлены с фоновыми и для наглядности представлены в таблице 1.

По результатам биохимических исследований установлено, что у телят первой опытной группы, на которых тестировался модифицированный йодинол, показатели содержания белка и резервной щелочности повысились и достигли средних физиологических значений. Показатель резервной щелочности по сути является индикатором обменных процессов в организме животных. В этот же период отмечена позитивная тенденция роста тиреоидных гормонов щитовидной железы. Применение фармакопейного йодинола на телятах второй группы не оказало столь выраженного метаболического действия. У животных этой группы показатели глюкозы и резервной щелочности были ниже физиологических значений.

Таблица 1 - Влияние йодинола в комплексе с янтарной кислотой и фармакопейного йодинола на биохимический статус телят при клинически выраженной йодной недостаточности

\begin{tabular}{|l|c|c|c|}
\hline \multicolumn{1}{|c|}{ Наименование показателя } & Фоновые данные & На 10 сутки & На 20 сутки \\
\hline Общий белок, г /л & $62,3 \pm 2,1$ & $69,3 \pm 2,5$ & $71.3 \pm 2,6$ \\
& $63,4 \pm 2,3$ & $64,7 \pm 2,2$ & $66,1 \pm 2,5$ \\
\hline Глюкоза, ммоль/л & $1,6 \pm 0,01$ & $2.1 \pm 0,01$ & $2,4 \pm 0.02$ \\
& $1,6 \pm 0,01$ & $1,8 \pm 0,02$ & $1.9 \pm 0,01$ \\
\hline Резервная щелочность, ммоль/л & $12,65 \pm 0,56$ & $18,31 \pm 1,07$ & $18,32 \pm 1,12$ \\
& $13,05 \pm 0,67$ & $14,23 \pm 0,73$ & $14,05 \pm 0,78$ \\
\hline СТ3 & $4,22 \pm 0,31$ & $6,31 \pm 0,47$ & $7,32 \pm 0,51$ \\
& $4,35 \pm 0,27$ & $5,26 \pm 0,32$ & $6,02 \pm 0,37$ \\
\hline СТ4 & $11,3 \pm 0,74$ & $14,9 \pm 1,07$ & $16,8 \pm 1,05$ \\
& $11,6 \pm 0,89$ & $13,7 \pm 1,02$ & $15,2 \pm 1,04$ \\
\hline
\end{tabular}

Примечание: верхняя строка - показатели у телят первой опытной группы; нижняя строка - показатели у второй опытной группы 


\section{ДИАГНОСТИКА БОЛЕЗНЕЙ И ТЕРАПИЯ ЖИВОТНЫХ, ПАТОЛОГИЯ, ОНКОЛОГИЯ И МОРФОЛОГИЯ ЖИВОТНЫХ}

На 20 сутки (спустя 10 дней после повторного введения препаратов) у телят первой группы полностью нормализовался показатель содержания глюкозы и резервной щелочности.

Таким образом, применение модифицированного препарата йодинол обеспечило быструю и эффективную нормализацию патобиохимических процессов при клинически выраженной йодной недостачности, с нарушением белкового и углеводного обмена. Применение фармакопейного йодинола не имело столь выраженных позитивных изменений.
Вывод. Сравнительное тестирование комплексного препарата на основе йодинола и янтарной кислоты и фармакопейного йодинола на телятах с клинически выраженным йоддефицитным состоянием свидетельствует о том, что модифицированный йодинол при внутримышечном введении обеспечивает высокую эффективность коррекции патобиохимических процессов и нормализацию гормональной функции щитовидной железы. Новые качества модифицированного йодинола открывают новые перспективы его применения в инфекционной и незаразной патологии.

\section{Список использованных источников}

1. Платонова Н.М. Йодный дефицит: современное состояние проблемы // Клиническая и экспериментальная тиреоидология. - 2015. - Т. 11. - № 1. - С.-12-20.

2. Платонова Н.М. Йоддефицитные заболевания (профилактика, диагностика, лечение и мониторинг): автореф. дисс. ... док. мед. наук. - М., 2010.

3. Манукало С.А., Шантыз А.Х. Йодная недостаточность в животноводстве // Ветеринария Кубани. - 2014. - № 5.

4. Мохнач В.О., Вальдман А.В., Евдокимов П.Д. Йодинол в медицине и ветеринарии. - Л.: Наука, 1967. - 187 с.

5.Коваленко А.Л., Белякова Н.В. Янтарная кислота: фармакологическая активность и лекарственные формы // Фармация. - 2000. - № 5-6. - С. 40-42.

6. Разработка и применение препаратов на основе янтарной кислоты / А.Ф. Лебедев, О.М. Швец, А.А. Евглевский и др. // Ветеринария. - 2009. - № 3. - С. 48-51.

7. Разработка нового поколения иммунометаболических препаратов и эффективность их применения в ветеринарии / А.А. Евглевский, Г.Ф. Рыжкова, О.М. Швец, Е.П. Евглевская // Вестник Курской государственной сельскохозяйственной академии. - 2010. - № 5. - С. 94-95.

8. Комплекс янтарная кислота с йодинолом: новые качества и перспективы применения / А.А. Евглевский, И.И. Михайлова, В.Н. Скира и др. // Ветеринарная патология. - 2015. - № 4. C. $37-43$.

9. Препараты йода-йодинол-неизвестные страницы, известное и новые качества при его модификации / Евглевский А.А., И.И. Михайлова, Е.П. Евглевская и др. // Вестник Курской государственной сельскохозяйственной академии. - 2015. - № 8. - С.94-95.

10. Способ профилактики йодной недостаточности и коррекции метаболизма у коров. Патент 2664438 Российская Федерация, МПК А61K 33/18; А61K 31/194; А61K 2121/00; А61K 2300/00.

11. Способ получения антисептического препарата с метаболической и гепатопротекторной активностью. Патент РФ №2486908.

\section{List of used sources}

1. Platonov N.M. Iodine deficiency: current state of the problem / Clinical and experimental thyroidology. - 2015. - V. 11. - № 1. - P.-12-20.

2. Platonov N.M. Iodine deficiency disorders (prevention, diagnosis, treatment and monitoring): author. diss. ... doc honey. sciences. - M., 2010.

3. Manukalo S.A., Shantyz A.Kh. Iodine deficiency in animal husbandry // Kuban veterinary medicine. - 2014. - № 5.

4. Mokhnach V.O., Valdman A.V., Evdokimov P.D. Iodinol in medicine and veterinary medicine. L .: Science, 1967. - 187 p.

5. Kovalenko A.L., Belyakova N.V. Succinic acid: pharmacological activity and dosage forms // Pharmacy. - 2000. - № 5-6. - P. 40-42. 
6. Development and use of preparations based on succinic acid / A.F. Lebedev, O.M. Shvets, A.A. Evglevsky and others. // Veterinary medicine. - 2009. - № 3. - P. 48-51.

7. Development of a new generation of immunometabolic drugs and the effectiveness of their use in veterinary medicine / A.A. Evglevsky, G.F. Ryzhkova, O.M. Shvets, E.P. Evglevskaya // Bulletin of the Kursk State Agricultural Academy. - 2010. - № 5. - P. 94-95.

8. Complex succinic acid with iodinol: new qualities and prospects of application / A.A. Evglevsky, I.I. Mikhailova, V.N. Skira, etc. // Veterinary Pathology. - 2015. - № 4. - P. 37-43.

9. Iodine preparations-iodinol-unknown pages, known and new qualities in its modification / Evglevsky A.A., I.I. Mikhailova, E.P. Evglevskaya and others // Bulletin of the Kursk State Agricultural Academy. - 2015. - № 8. - P. 94-95.

10. Method for the prevention of iodine deficiency and correction of metabolism in cows. Patent 2664438 Russian Federation, IPC A61K 33/18; A61K 31/194; A61K 2121/00; A61K 2300/00.

11. A method of obtaining an antiseptic drug with metabolic and hepatoprotective activity. The patent of the Russian Federation №2486908. 